\title{
DISTRIBUTION AND GENETIC VARIABILITY OF AVIAN HEPATITIS E VIRUS ON POULTRY FARMS IN EX-USSR
}

\author{
A.V. SPRYGIN, Z.B. NIKONOVA, YU.YU. BABIN, N.P. ELATKIN, \\ A.V. PISKUNOV, V.N. IRZA
}

Federal Centre for Animal Health, FGBU «VNIIZZh», mkr. Yur'evets, Vadimir, 600901 Russia, e-mail sprygin@arriah.ru, piskunov@arriah.ru, irza@arriah.ru

Received August 20, 2013

\section{Abstract}

Russian commercial poultry industry is tightly tied to international trade. To date, avian hepatitis E virus (aHEV) has been isolated in Australia, US, Spain, Hungary, etc., being a serious threat to commercial poultry. In hens, aHEV affects liver and immune system, namely spleen and thymus, disrupting homeostasis and hematological parameters. In Russia, aHEV genetic identification was first reported in 2009 , but the current epizootic situation in poultry remains to be unknown. In this paper we report the results of genetic analysis of 415 liver samples from hens and broiler chicks aged 4-56 weeks. The samples were obtained from 68 commercial farms in 36 regions of the Russian Federation and 4 commercial farms from Belarus, Kazakhstan and Ukraine during 2009 to 2012. A total of 14 isolates were detected and sequenced. Isolates of aHEV were detected in both clinically healthy and affected chickens. No agents causing similar clinical signs, i.e. leucosis virus, Marek's disease virus and adenovirus, were identified. In Russia, aHEV was isolated in Amurskaya, Vologodskaya, Ivanovskaya, Kaluzhskaya, Moskovskaya, Samarskaya, Saratovskaya provinces, and also in the Republic of Mari El. Ross 308 hens showed highest PCR-positive rates (8 of 14 isolates). According to RT-PCR analysis of capsid protein gene (ORF2), aHEV18198, aHEV19555, aHEV16211, aHEV18479 and aHEV18481 of 14 Russian isolates fall within European genotype 3. The aHEV16211, aHEV18479, aHEV18481 isolates are related to Chinese (China-09-G57), US (NY449, CA697A) and European (06-4582) isolates, and aHEV18198 and aHEV19555 are related to those from Australia and USA (Guelph01, CA518.3). Of 14 aHEV isolates studied, 7 samples formed a distinct genetic group. Two more isolates, aHEV18381 and aHEV18505, group outside the three genotypes described. Overall, the pool of HEV isolates identified in Russian chicken flocks consists of isolates belonging to European genotype 3 and isolates not yet assigned to a specific genotype. The analysis of genetic variability of aHEVs isolates from different countries strongly suggests that the current classification into genotypes by geographical origin should be revised.

Keywords: PCR, hepatitis E, hens.

To date the hepatitis E in poultry has been reported in Australia (1), the United States (2), Spain (3), Hungary (4), Russia (5), etc. Its causative agent, the aHEV (Hepevirus: Hepeviridae) is a non-enveloped virus with a singlestranded, positive-sense RNA genome (6) that is approximately $6600 \mathrm{bp}$ in size and contains three open reading frames (ORFs) (7). 5'-end ORF1 encodes the nonstructural polypeptide with several domains, including a methyltransferase domain, a papain-like cystein protease domain, a helicase domain and a RNAdependent RNA polymerase domain (8), and ORF2 and ORF3 encode the capsid protein and a posphoprotein, respectively (9-11).

aHEV attacks liver, as well as spleen and thymus involved in immune response, and constitutes a real threat to poultry commercial farming. Big liver and spleen disease (BLS) and hepatit-splenomegaly syndrome (HSS) are reported as manifestations of the infection. aHEV is shown to cause deep disturbance in homeostasis, especially in hematological indexes (12).

In Sverdlovsk Province the antibodies against aHEV were detected in 2004 in blood serum of $18.3 \%$ hens indicating aHEV circulation in flocks (13). In Russia aHEV has been first identified genetically in 2009 (5), nevertheless, the prevalence and current epizootic situation are still poor studied.

In this paper a large-scale survey for aHEV and its genetic variability 
based on the capsid protein gene sequencing are reported.

Technique. From 2009 to 2012415 specimens of liver were sampled from Rodonit 3, Ross 308 and Hubbard ISA laying hens and broilers of different age in 68 poultry commercial farms from 36 regions of the Russian Federation and 4 commercial farms from Belarus, Kazakhstan and Ukraine.

Viral RNA was isolated using RIBO-sorb kit (Russia) composed of the lysing reagent, rinse and elution buffers, and silicate sorbent, according to manufacturer's recommendation. The RT-PCR primers and protocol described (14) were modified.

A $242 \mathrm{nt}$ fragment of aHEV capsid protein gene was sequenced on a ABI Prism 3130 (Applied Biosystems, USA) with ClustalW sequence alignment algorithm (BioEdit v. 7.0.5.3). The Neighbor-Joining bootstrapped trees $(n=1000)$ were generated using MEGA software version v. 3.1 (available at http://megasoftware.net). The aHEV sequences used for alignment were retrieved from GenBank (the accession numbers FM872312 to FM872320, FM872322 to FM872330, FN557166 to FN557172, and AM943646), and also a swine HEV capsid protein gene sequence as an external control.

Results. Analysis of the samples. By RT-PCR (14) a total of 14 aHEV isolates were detected in poultry with big liver syndrome and in apparently healthy birds unchanged in egg production and viability (Table).

Characteristics of the avian hepatitis virus E isolates from poultry farms in ex-USSR (2009-2012)

\begin{tabular}{|c|c|c|c|c|c|c|}
\hline Isolate & $\begin{array}{l}\text { Country and the region } \\
\text { of origin }\end{array}$ & Date & $\begin{array}{l}\text { Clinical } \\
\text { symptoms }\end{array}$ & Cross & $\begin{array}{l}\text { Poultry age, } \\
\text { days }\end{array}$ & $\begin{array}{l}\text { GenBank ac- } \\
\text { cession number } \\
\text { of a sequence }\end{array}$ \\
\hline \multicolumn{2}{|c|}{ aHEV16050 Kazakhstan, no data } & 2009 & Enlarged liver & Rodonit 3 & Pooled sam- & JQ814691 \\
\hline \multicolumn{2}{|c|}{ aHEV16211 Russia, Vologodskaya Province } & 2010 & $\begin{array}{l}\text { Enlarged liver and } \\
\text { spleen, liver hemor- } \\
\text { rhage }\end{array}$ & Ross 308 & 230 & JQ814690 \\
\hline \multirow{6}{*}{\multicolumn{2}{|c|}{$\begin{array}{l}\text { aHEV16279 Russia, Kaluzhskaya Province } \\
\text { aHEV18196 Russia, Ivanovskaya Province } \\
\text { aHEV18198 Russia, Saratovskaya Province } \\
\text { aHEV18381 Russia, Moscow Province } \\
\text { aHEV18383 Russia, Amurskaya Province } \\
\text { aHEV18479 Russia, Vologodskaya Province }\end{array}$}} & 2011 & Enlarged liver & Ross 308 & 237 & JQ814692 \\
\hline & & 2012 & No symptoms & Ross 308 & 117,350 & JQ814688 \\
\hline & & 2012 & No symptoms & Hubbard ISA & 315 & JQ814689 \\
\hline & & 2012 & No symptoms & no data & no data & - \\
\hline & & 2012 & No symptoms & Hubbard ISA & $30-36$ & - \\
\hline & & 2012 & $\begin{array}{l}\text { Enlarged liver and } \\
\text { spleen }\end{array}$ & Ross 308 & 193 & - \\
\hline \multicolumn{2}{|c|}{ aHEV18481 Russia, Vologodskaya Province } & 2012 & $\begin{array}{l}\text { Enlarged liver and } \\
\text { spleen }\end{array}$ & Ross 308 & 250 & - \\
\hline \multicolumn{2}{|c|}{ aHEV18505 Russia, no data } & 2012 & No symptoms & no data & н.д. & - \\
\hline \multicolumn{2}{|c|}{ aHEV19551 Russia, Marii El Republic } & 2012 & No symptoms & Ross 308 & 241 & - \\
\hline \multicolumn{2}{|c|}{ aHEV19553 Russia, Marii El Republic } & 2012 & No symptoms & Ross 308 & 394 & - \\
\hline \multirow{2}{*}{\multicolumn{2}{|c|}{$\begin{array}{l}\text { aHEV19555 Russia, Saratovskaya Province } \\
\text { aHEV20088 Russia, Saratovskaya Province }\end{array}$}} & 2012 & No symptoms & Hubbard ISA & 306 & - \\
\hline & & 2012 & No symptoms & Ross 308 & 224 & - \\
\hline
\end{tabular}

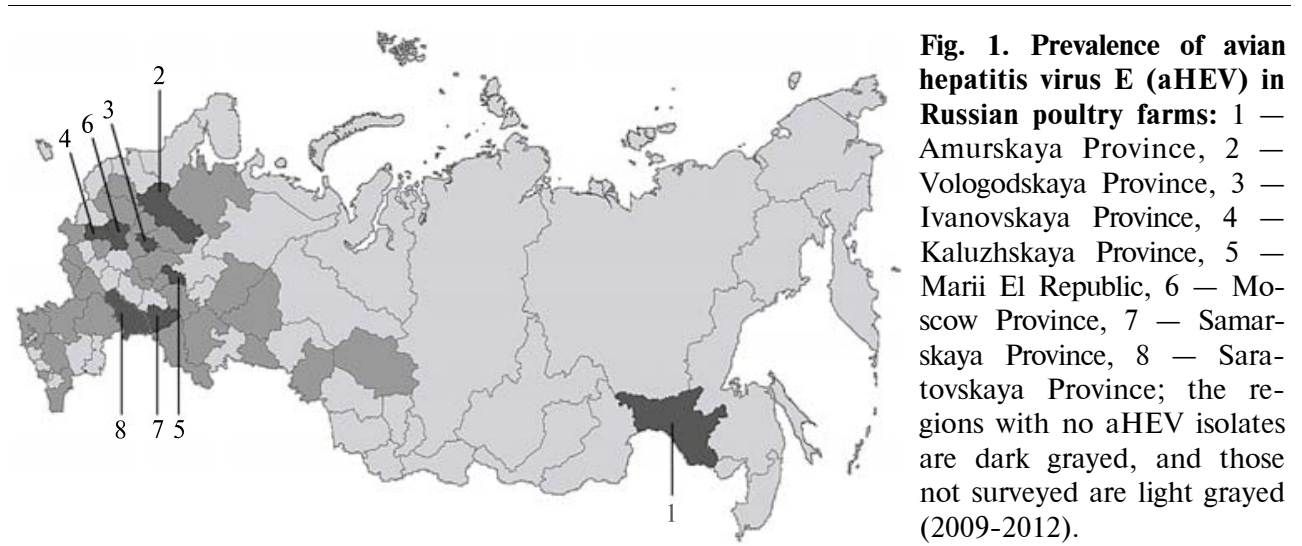

The territories of the Russian Federation where aHEV has been isolated 
are mapped hereinabove (Fig. 1).

Phylogenetic analysis. In total of 14 obtained aHEV isolates of different origin and location the capsid gene fragment was sequenced and subjected to phylogenetic analysis (Fig. 2).

According to publications, there are three different genotypes of aHEV, namely Australian (genotype 1), American (genotype 2) and European (genotype 3) $(15,16)$. Besides, a Hungarian isolate HU-16773 also shown on the dendrogam (see Fig. 2) is considered a potentially individual genotype.

The Russian isolates aHEV18198, aHEV19555, aHEV16211, aHEV18479 and aHEV18481 apparently belong to the European genotype 3 (see Fig. 2). At that three ones, the aHEV16211, aHEV18479 and aHEV18481, were genetically similar to the aHEV isolates of the genotype 3 from China (China-09-G57, etc.), the United States (NY449, CA697A) and Europe (06-4582, etc.), and aHEV18198 and aHEV19555 were similar to the Australian and Canadian isolates (05-6745-2, Guelph01). Thus the Russian isolates shared 84.0-97.6 \% homology with the other representatives of the genotype 3.

Nevertheless, among 14 recovered Russian isolates the aHEV16050, aHEV19553, aHEV19551, aHEV18196, aHEV16279, aHEV20088 and aHEV18383 differed significantly from the other described strains and isolates of the virus and segregated into a distinct genetic lineage (see Fig. 2). They shared 89.6$99.2 \%$ sequence homology with each other compared to 76.0-87.2\% nucleotide identity with the other aHEV strains and isolates.

The aHEV18505 and aHEV18381 Russian isolates did not segregate into any described genetic group on the dendrogram and shared $83.2 \%$ similarity to each other while their sequence identity with the rest used strains and isolates ranged from 76.8 to $84.8 \%$.

Russian poultry industry is tightly tied to international trade, particularly incubator eggs and day-old chicks for broiler and laying hen flocks are being imported. Therefore, a wide prevalence of aHEV in Australia (1), USA (2), Spain (3), Hungary (4), Korea, Czech Republic, England, Ukraine, Poland, Israel (16) and China necessitates studying the epizootic situation in Russia. In the Russian commercial poultry flocks a hepato- and splenomegaly, hepatic subcapsular hematomas, a breakable consistence of the liver, bloody liquid in abdominal cavity, drop in egg production and increased mortality rates were earlier reported but only recently the eHEV was identified as an etiological agent (5).

Of note, the aHEV was detected both in sick poultry with affected livers and in clinically healthy birds (see Table), being in line with the other data reported $(3,14,16,17)$. So X.J. Meng et al. (17) found out the aHEV infection to be mostly subclinical. In our survey a majority of the recovered Russian isolates, exactly 9 of the 14 samples reported herein were detected in the individuals with no signs of illness. There are the evidences that clinical manifestations in birds may be influenced by a viral dose and strain specificity, by associated pathogens, and also by the poultry age, breed and vaccination $(3,7,16)$. Thus, the suggestion was reasonable that the hens with liver pathology might be infected at high viral dose and influenced by some stress factors. However, no associated agents causing similar manifestations such as leucosis virus, Marek's diseases virus or adenovirus were detected (data not shown). All tested probes have been sampled from the hens over the age of 200 days. Importantly, a majority of aHEV isolates, exactly 8 of the 14, were detected in Ross 308 cross.

According to similarity of the nucleotide sequence of ORF2 capsid protein gene 7 of 14 Russian aHEV isolates segregated into a genetic group to which a lineage of another two isolates was close (see Fig. 2). 


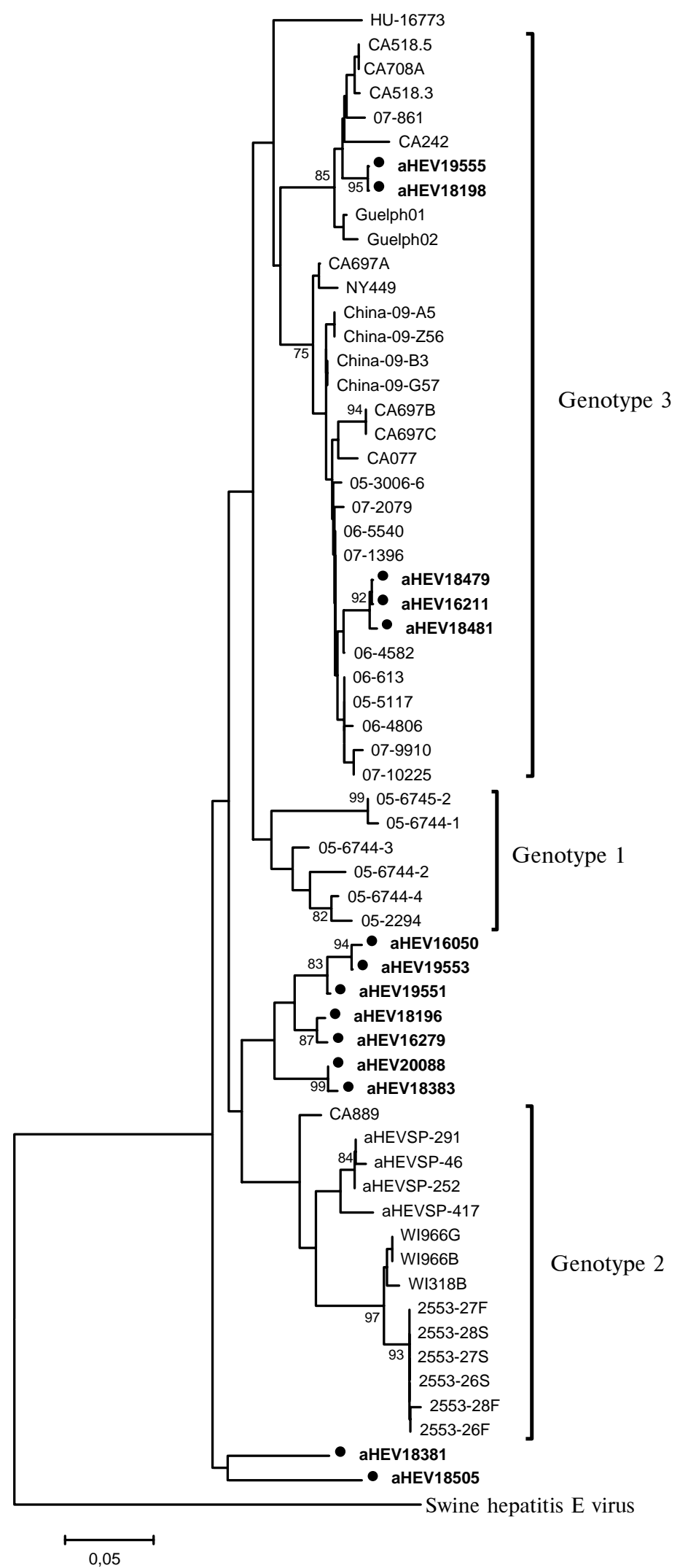

Fig. 2. Dendrogram constructed with the capside gene sequences of avian henatitis virus $E$ (aHEV) of different origin (bootstrap values $\geq 75 \%$; the 14 aHEV isolates marked bold have been recovered on the poultry farms in the Russian Federation, Belarus, Kazakhstan and Ukraine from 2009 to 2012; 
Based on previous phylogenetic data three aHEV genotypes are suggested according to the geographic origin, i.e. the United States, Australia and Europe, $(15,16)$, and the Hungarian aHEV is considered a candidate genotype 4. Of note, the Russian isolates (see Fig. 1), too, can probably segregate into a specific genotype, however, the genome sequencing should be copleted for elucidation.

Z.F. Sun et al. (14) reported 76-100 \% similarity among aHEV isolates from the US compared to their 48-54 \% identity to swine and human HEV. I. Bilic et al. (15) found out the nucleotide sequence homology of aHEV capside gene fragment ranging from 84.0 to $100 \%$ among the European isolates and from 85.1 to $99.4 \%$ among the Australian isolates. The similarity extents of 80.6-85.7 \%, 76.6-82.9 \%, and 76.0-80.6 \% were detected between European and Australian isolates, European and the US isolates, and Australian and the US isolates, respectively.

Three Russian isolates of European genotype 3, the aHEV16211, aHEV18479 and aHEV18481, are the most close to Australian 06-4582 isolate (see Fig. 2), and two isolates, the aHEV18198 and aHEV19555, are closer to Australian and the US isolates, the Guelph01 and CA518.3. The extent of sequence identity of these five Russian isolates to other members of the genotype 3 group reached 85.6-96.8\% (see Fig. 2), and other 9 isolates were not clustered with any currently known genotypes. Thus in Russia both aHEV isolates of European genotype 3 and those not yet assigned to a specific genotype are circulating. Our data evidence the previously reported high genetic heterogeneity of aHEV strains circulating worldwide $(14,15)$.

Variability of aHEV isolates from different countries strongly suggests the geographically based classification to be revised $(15,16)$. Despite the distance between Korea and Australia, the Korean aHEV isolates belong phylogenetically to Australian genotype group (18). The same is reported for aHEV isolates from Europe and China. To clarify possible reasons for genetic relationship between the geographically remote isolates more viral samples should be analyzed.

In Russia aHEV seroconversion was first reported in 2004 for Ekaterinburg region by Ibrakhim El-Morsi (13) based on $18.3 \%$ seropositive hens in the flocks surveyed. Nevertheless, these results indirectly indicated aHEV circulation in flocks, and the estimation was incomprehensive. In other countries the aHEV seroprevalence indicates its wide distribution. $(1,19)$. Particularly, in Korea antibodies against aHEV were detected in $57 \%$ hens (18). In the United States $71 \%$ of 1276 blood serum samples obtained from 76 flocks were seropositive (7). The seroprevalence was higher in the hens over the age of 18 weeks rather than in young poultry (7). In out survey all hens with positive PCR-test were seropositive (data not shown). Moreover, specific antibodies were also identified in RT-PCR-negative blood serum samples. Therefore, aHEV seems to circulate in hen flocks very widely.

According to observations of P. Billam et al. (20), the aHEV natural infection can be first detected in hens aged about 12 weeks with the viremia occurred from 14 to 17 weeks of age. In the hens over 20 weeks of age the PCRpositive probes were low in number despite the high seroprevalence, probably due to viral clearance at sampling. In our survey aHEV was detected in 4 to 56 week-old hens (see Table).

Thus, using RT-PCR a total of 14 aHEV isolates, exactly 13 from Russia and 1 from Kazakhstan, together referred to as the Russian isolates, have been recovered. Majority of the isolates, exactly 9 of 14 reported, were detected in hens with no manifestations of liver and spleen pathology and no decrease in egg production and viability. Of 14 aHEV isolates studied, 7 samples formed a dis- 
tinct genetic group. Two more isolates group outside the three genotypes described. The rest 5 isolates group with the European genotype 3 aHEVs. Overall, the pool of aHEV isolates identified in Russian chicken flocks consists of isolates belonging to European genotype 3 and isolates not yet assigned to a specific genotype. Our data are in line with the reported high genetic variability in aHEV strains circulating worldwide. The analysis of genetic variability of aHEVs isolates from different countries strongly suggests that the current classification into genotypes by geographical origin should be revised.

\section{REFERENCES}

1. P a y e C.J. Big liver and spleen disease. In: Diseases of poultry. Y.M. Saif, H.J. Barnes, J.R. Glisson, A.M. Fadly, L.R. McDougald, D.E. Swayne (eds.). Ames, Iowa State Press, 2003: 1184-1186 (doi: 10.1016/S0378-1135(99)00067-X).

2. S hiva pras ad H.L. Hepatitis splenomegaly syndrome. In: Diseases of poultry. Y.M. Saif, H.J. Barnes, J.R. Glisson, A.M. Fadly, L.R. McDougald, D.E. Swayne (eds.). Ames, Iowa State Press, 2003: 1186-1188.

3. Peralta B., Biarnes M., Ordonez G., Porta R., Martin M., MateuE., $\mathrm{P}$ i n a S., Men g X.J. Evidence of widespread infection of avian hepatitis E virus (avian HEV) in chickens from Spain. Vet. Microbiol., 2009, 137: 31-36 (doi: 10.1016/j.vetmic.2008.12.010).

4. Morrow C.J., S a mu G., Mátrai E., Klausz A., Wood A.M., Richter S., Jas kulska B., Hess M. Avian hepatitis E virus infection and possible associated clinical disease in broiler breeder flocks in Hungary. Avian Pathol., 2008, 37: 527-535 (doi: 10.1080/03079450802356946).

5. I r z a V., S p rygi n A. Big liver and spleen syndrome is a new viral disease in Russian chicken flocks. Agricultural Biology, 2012, 4: 73-77 (http://www.agrobiology.ru/4-2012irza-eng.html).

6. Emerson S.U., Anderson D., Arankalle A., Meng X.J., Purdy M., Schlau d e r G.G., T s a rev S.A. Hepevirus. In: Virus taxonomy. VIII th Report of the ICTV. C.M. Fauquet, M.A. Mayo, J. Maniloff, U. Desselberger, L.A. Ball (eds.). London, Elsevier/Academic Press, 2004: 851-855.

7. Huang F.F., Sun Z.F., Emerson S.U., Purcell R.H., Shivaprasad H.L., Pierson F.W., T oth T.E., M e ng X.J. Determination and analysis of the complete genomic sequence of avian hepatitis E virus (avian HEV) and attempts to infect rhesus monkeys with avian HEV. J. Gen. Virol., 2004, 85: 1609-1618 (doi: 10.1099/vir.0.79841-0).

8. Koon in E.V., Gorbale nya A.E., Purdy M.A., Rozanov M.N., Reyes G.R., B radle y D.W. Computer-assisted assignment of functional domains in the nonstructural polyprotein of hepatitis E virus: delineation of an additional group of positive-strand RNA plant and animal viruses. PNAS USA, 1992, 89: 8259-8263.

9. Tam A.W., S mith M.M., Guerra M.E., Huang C.C., Bradley D.W., Fry K.E., R e y e s G.R. Hepatitis E virus (HEV): molecular cloning and sequencing of the full-length viral genome. Virology, 1991, 185: 120-131 (doi: 10.1016/0042-6822(91)90760-9).

10. T y a g i S., Korka y a H., Z a frulla h M., J a m e el S., La 1 S.K. The phosphorylated form of the ORF3 protein of hepatitis E virus interacts with its non-glycosylated form of the major capsid protein, ORF2. J. Biol. Chem., 2002, 277: 22759-22767 (doi: 10.1074/jbc.M200185200).

11. Z a frullah M., Ozde ne r M.H., P a nda S.K., J a mee $1 \mathrm{~S}$. The ORF3 protein of hepatitis E virus is a phosphoprotein that associates with the cytoskeleton. J. Virol., 1997, 71: 9045-9053.

12. To k a r e O.I. Patomorfologicheskaya kharakteristika timusa i selezenki kur pri virusnom gepatite E. Avtoreferat kandidatskoi dissertatsii [Pathomorphological features of thymus and spleen in hens with hepatitis E. PhD Thesis]. Voronezh, 2012.

13. $\mathrm{E} 1 \mathrm{M}$ orsi $\mathrm{Ibrakhim}$. Rasprostranenie gepatita $E$ sredi naseleniya endemichnykh $i$ neendemichnykh regionov mira. Avtoreferat kandidatskoi dissertatsii [Distribution of hepatitis $\mathrm{E}$ in population of endemic and non-endemic territories. PhD Thesis]. Moscow, 2004.

14. Sun Z.F., Larsen C.T., Dunlop A., Huang F.F., Pierson F.W., Toth T.E., Me ng X.-J. Genetic identification of avian hepatitis E virus (HEV) from healthy chicken flocks and characterization of the capsid gene of 14 avian HEV isolates from chickens with hepatitis-splenomegaly syndrome in different geographical regions of the United States. J. Virol., 2004, 85: 693-700 (doi: 10.1099/vir.0.19582-0).

15. Bilic I., Jaskulska B., Basic A., Morrow C.J., Hess M. Sequence analysis and comparison of avian hepatitis E viruses from Australia and Europe indicate the existence of different genotypes. J. Gen. Virol., 2009, 90: 863-873 (doi: 10.1099/vir.0.007179-0).

16. Marek A., Bilic I., Prok ofieva I., Hess M. Phylogenetic analysis of avian hepatitis E virus samples from European and Australian chicken flocks supports the existence of a different genus within the Hepeviridae comprising at least three different genotypes. Vet. Microbiol., 2010, 145: 54-61 (doi: 10.1016/j.vetmic.2010.03.014).

17. Meng X.J., Shivaprasad H.L., P y n e C.J. Avian hepatitis E virus infections. In: Dis- 
eases of poultry. Y.M. Saif, J.R. Fadly, L.R. McDougald, L.K. Nolan, D.E. Swayne (eds.). Blackwell Publishing Press, 2008: 443-452.

18. Kwon H.W., Sung H.W., Meng X.J. Serological prevalence genetic identification and characterization of the first strains of avian hepatitis E virus from chickens in Korea. Virus Genes, 2012, 45(2): 237-245 (doi: 10.1007/s11262-012-0761-6).

19. Todd D., Mawh in ney K.A., Mc Ali inde n V.A., Douglas A.J. Development of an enzyme-linked immunosorbent assay for the serological diagnosis of big liver and spleen disease. Avian Dis., 1993, 37: 811-816 (doi: 10.2307/1592034).

20. B ill a m P., S u n Z.F., M e ng X.J. Analysis of the complete genomic sequence of an apparently avirulent strain of avian hepatitis E virus (avian HEV) identified major genetic differences compared with the prototype pathogenic strain of avian HEV. J. Gen Virol., 2007, 88(Pt 5): 1538-1544 (doi: 10.1099/vir.0.82754-0). 